\title{
Agarwal PolyLoop Ligation Technique for the Management of the Distal Ureter during Laparoscopic Assisted Nephroureterectomy
}

\author{
Dinesh K. Agarwal \\ Urology Unit, The Royal Melbourne Hospital, Melbourne, VIC, Australia
}

\author{
Key Words \\ Laparoscopy • Nephroureterectomy • Ureter • Endoscopy • \\ Transitional cell carcinoma
}

\begin{abstract}
Objective: Management of the distal ureter during radical nephroureterectomy remains a controversial issue. This article describes a simple endoscopic PolyLoop ligation technique for managing the distal ureter during radical nephroureterectomy. Technique: This endoscopic technique was used in 6 cases to manage the distal ureter during laparoscopic-assisted radical nephroureterectomy. The distal ureter with en bloc bladder cuff was managed endoscopically. The distal ureteric orifice with $1 \mathrm{~cm}$ bladder cuff was circumscribed using a Collins knife. Commercially available, Olympus detachable PolyLoop was used to ligate the ureteric stump to avoid urine spillage from the upper tract. Once ureteric stump was ligated with a PolyLoop, the distal ureter was mobilized by dividing the periureteric adhesions using a Collins knife. Results: Distal ureter was managed successfully in all 6 cases using commercially available detachable Polyloop from Olympus. There were no perioperative com-
\end{abstract}

\section{KARGER}

Fax +41613061234

E-Mail karger@karger.com

www.karger.com
(C) 2020 The Author(s)

Published by S. Karger AG, Basel Open access

This article is licensed under the Creative Commons AttributionNonCommercial-NoDerivatives 4.0 International License (CC BYNC-ND) (http://www.karger.com/Services/OpenAccessLicense). Usage and distribution for commercial purposes as well as any dis-
Usal tribution of modified material requires written permission. plications relating to this technique. Conclusion: The PolyLoop ligation technique offers a simple and safer alternative to manage the distal ureter during radical nephroureterectomy.

(c) 2020 The Author(s)

Published by S. Karger AG, Basel

\section{Introduction}

Upper tract urothelial carcinoma is rare, representing only $5 \%$ of all urothelial tumors [1]. Radical nephroureterectomy with excision of bladder cuff remains the gold standard for the management of non-metastatic upper tract urothelial carcinoma [2]. This procedure has traditionally been performed by open method. Laparoscopic nephroureterectomy has become a popular and less invasive option with similar oncological outcomes [3]. With the introduction of robotic technology in surgery, there seems to be an increasing application of robotic technique to perform radical nephroureterectomy [4]. Management of the distal ureter still remains a dilemma and various techniques have been described in the

Dinesh K. Agarwa

Urology Unit

The Royal Melbourne Hospital

300 Grattan Street,

Parkville, VIC 3050 (Australia)

E-Mail dineshagarwal@bigpond.com 


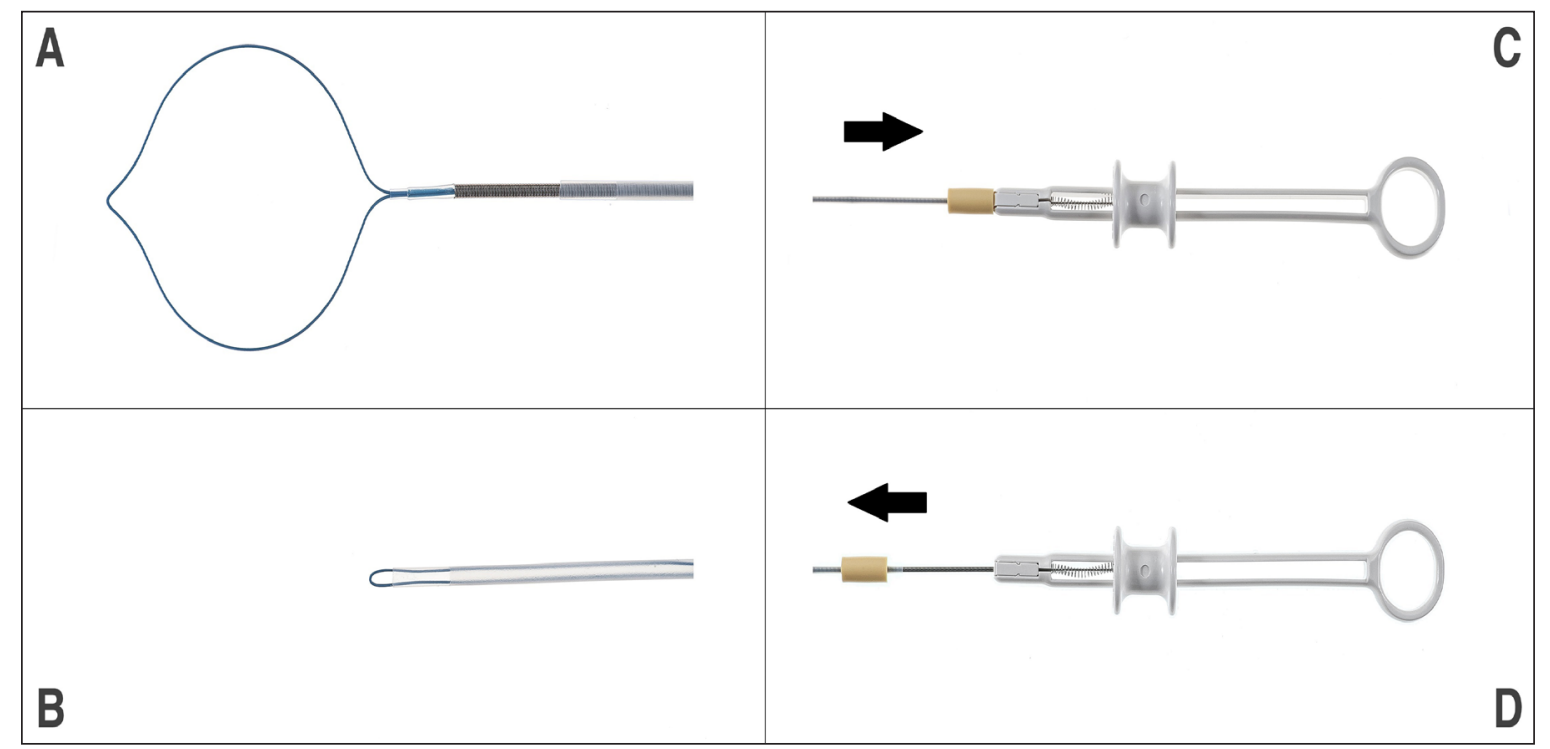

Fig. 1. Olympus PolyLoop. A Loop outside the plastic sheath; B Loop is inside the plastic sheath; C, D Yellow cylinder in the handle moves loop in and out of the plastic sheath.

literature [5-16]. It remains uncertain which distal ureter management technique provides the best perioperative or oncological outcome.

The author has previously published a technique of endoscopic loop ligation and detachment of the distal ureter using a preformed 0 PDS II endoloop (Ethicon, Sommerville, NJ) [12]. This technique has been modified and this report describes the management of distal ureter during nephroureterectomy using a commercially available detachable PolyLoop from Olympus.

\section{Methods and Design}

\section{Detachable Loop Ligating Device (PolyLoop)}

The detachable PolyLoop is manufactured by Olympus Medical System Corp., Tokyo, Japan (HX-400U-30) (fig. 1). This device is used in gastroenterology during polypectomy to control the bleeding. This device also appears to be suitable for ligation of the bladder cuff during nephroureterectomy. The PolyLoop is composed of an outer plastic sheath and an inner metal coil around a central cable with a hook that houses the nylon loop. The loop's diameter is $30 \mathrm{~mm}$ and has a silicone rubber stopper that permits desired amount of the tightening of the loop. The device has a working length of $230 \mathrm{~cm}$ and requires a minimum working channel of $2.8 \mathrm{~mm}$ diameter. This device can be easily passed through a 25Fr cystoscope. The loop can be easily pulled in and out of the outer plastic sheath using the yellow cylinder without distorting the memory of the loop. This function is helpful in placing the loop around the bladder cuff. The loop can then be tightened and released using the slider at the proximal end of the device.

Endoscopic PolyLoop Ligation and Release of the Distal Ureter Cystoscopy is performed in a standard fashion to rule out any active bladder tumor disease. A resectoscope mounted with a Collins knife is used to score the ureteric orifice circumferentially with a 1-cm bladder cuff (fig. 2A). The continuous flow resectoscope is preferred to keep bladder pressure low. The dissection is carried through the partial thickness of the bladder, taking care not to detach the ureter at this stage. This step is crucial to avoid any extravasation of the urine which may cause the tumor seeding into perivesical space. The circumscribed ureteric orifice stands out like a mushroom. Care is taken not to detach the ureter at this stage as it may recede back into the wound and ligation of ureteric stump may become difficult.

The 25Fr cystoscope with Albarran deflecting bridge is then advanced into the bladder. The PolyLoop device is passed through the working channel after pulling the loop back into the outer plastic sheath. Once the PolyLoop device is in the bladder, the loop is pushed out of the plastic sheath using the yellow cylinder. The loop is positioned over the ureteric stump (fig. 2B) and the loop size can be adjusted by moving the outer plastic sheath back and forth over the loop with the yellow cylinder. Once the loop is in the proper position around the ureteric stump, it is gently tightened. The loop tightening is a 2 -stage procedure. In the first stage, the loop is tightened by advancing the outer plastic sheath over the loop up to the ureteric stump using the yellow cylinder. 


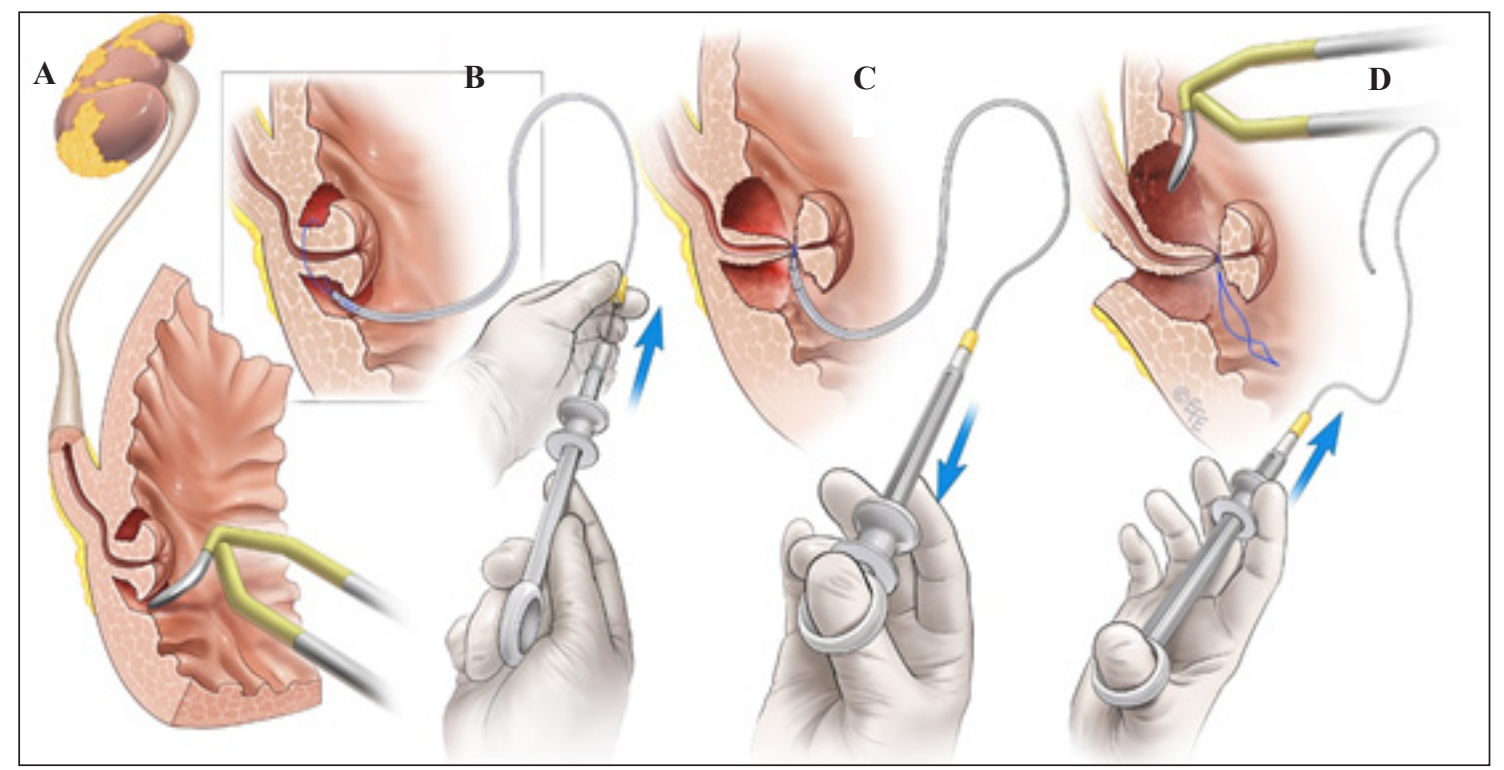

Fig. 2. Technique of the distal ureter management by PolyLoop ligation. A Ureteric orifice with bladder cuff is dissected as described with Collins knife; B PolyLoop is placed around the ureteric stump and the loop is gently tightened by advancing plastic sheath over the loop using yellow cylinder; $\mathbf{C}$ Loop is secured by sliding the silicone rubber stopper over the loop by pulling the slider proximally; $\mathbf{D}$ The loop is detached by pushing the slider distally. Ureteric stump is further dissected and detached from the bladder using Collins knife.

In this way, the loop is kept tight by the outer sheath but is not yet secured. In the second stage, the loop is tightened and secured by sliding the silicone rubber stopper over the loop inside the plastic sheath by pulling the slider proximally (fig. $2 \mathrm{C}$ ). Once the ureteric stump is successfully ligated, the loop is detached by pushing the slider distally until it stops to extend the hook from the coil sheath (fig. 2D).

The distal ureter is now detached from the bladder using the Collins knife. Extravasation of the irrigating fluid at this stage of dissection is minimized by avoiding overdistention of the bladder and keeping the height of irrigating fluid to a minimum. The bladder is drained with a $18 \mathrm{Fr}$ Foley catheter.

Nephrectomy, en bloc Specimen Retrieval and Bladder Closure The nephrectomy is performed with a standard laparoscopic transperitoneal approach. In brief, the patient is positioned and secured in the $45^{\circ}$ semiflank position. This position allows rotation of the patient to either side when required. During the laparoscopic procedure, the table can be rotated so that the patient can be positioned close to a $90^{\circ}$ lateral position if required. The kidney is mobilized and ureter is dissected to the level of pelvic brim and left intact. The operating table is now rotated to make the patient as flat as possible. A small Gibson type incision is employed in the ipsilateral groin and distal ureter is detached extraperitoneally by dividing the remaining adhesions under the vision. Identification of the loop at the distal end ensures the complete excision of direct ureter. The bladder defect is closed in two layers under the vision and the specimen is removed en bloc. The wound is closed in layers with a Jackson-Pratt drain left in the perivesical space.

\section{Results}

This technique was used in 6 patients: 3 males and 3 females. Age ranged from 52 to 76 years (mean 64.2 years). Tumor was in the renal pelvis in 4 patients and in the proximal ureter in 2 patients. PolyLoop ligation of the distal ureter was successful in all patients. Mean surgical time for cystoscopic procedure was 27 minutes (range 22-46 minutes). There was minimal blood loss during the bladder procedure. No patients required blood transfusion. Drain was removed on day 2 and Foley catheter was removed on day 7 . Histopathology showed pTaG2 disease in 4 patients, pT1G2 disease in 1 patient and pT1G3 disease in 1 patient. Outer and distal margins were clear in all patients. Follow-up ranged from 12 to 30 months. Surveillance cystoscopy showed bladder recurrence in 2 patients. There was no tumor recurrence in the perivesical space or at the site of detachment of the ureteric orifice. 


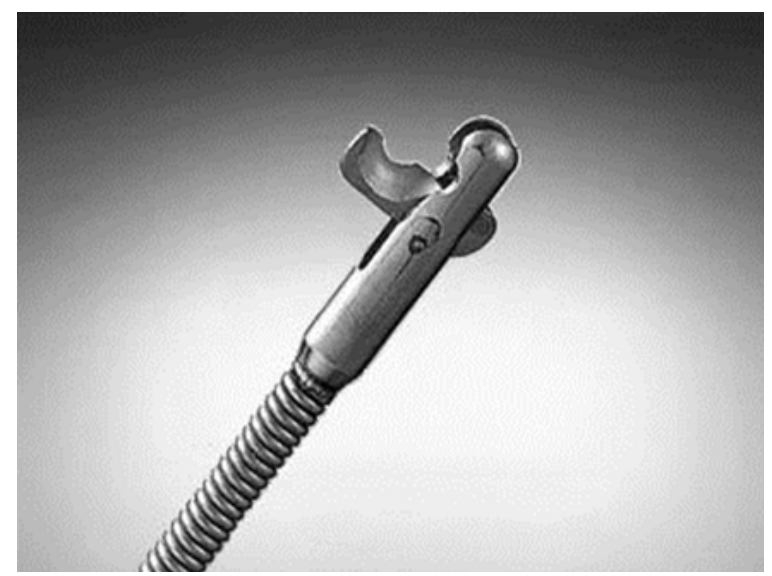

Fig. 3. Loop cutter.

\section{Discussion}

The controversy of the management of the distal ureter during laparoscopic nephroureterectomy is far from over. Several techniques for distal ureter and bladder cuff resection have been described. No prospective, randomized comparisons exist to compare the perioperative and oncological outcomes of various techniques for managing distal ureter. Open resection technique is considered the gold standard against which all other techniques are compared [10]. However, the open technique is invasive and other less invasive endoscopic techniques are commonly used. The pluck technique is one of the oldest endoscopic methods for distal ureter management, originally described in 1952 [5]. This technique involves resection of ureteric orifice deep into extravesical fat and subsequent "plucking" of the distal ureter from above. The main concern of the pluck technique is locoregional tumor recurrence with spillage of tumor cells from an unclamped ureter into the perivesical space. There are several reports on local recurrence following the pluck technique [17-19]. Another concerning feature of the pluck technique is the potential for leaving behind a segment of incompletely resected ureter as there is no marker at the distal end. To avoid the risk of tumor spillage from the unclamped ureter, various modifications of ureteral occlusion have been described [8, 9, 11, 12, 14-16]. Gill et al. [8] described their technique of ligating the ureter transvesically with an endoloop ligature (Ethicon, Sommerville, NJ, USA) assisted with 2 needlescopic ports placed into the bladder. This technique seems to be technically challenging. Compared to the Gill's technique
[8], Agarwal et al. [12] described a much simpler and purely transurethral technique of occluding the ureter with the endoloop. Ureteral intussusception technique [6] appears to be more of a historical approach rather than having any place in modern literature. Pure laparoscopic technique involves either extravesical stapling of the distal ureter or complete laparoscopic dissection of ureter and bladder cuff and suture closure of the bladder defect $[7,13]$. However, the pure laparoscopic technique is more dificult to perform and port site seeding has been reported [20]. Laparoscopic extravesical stapling approach has been associated with cystoscopically appreciable remnant of the resected ureteric orifice in $50 \%$ of the cases [21].

The PolyLoop ligation technique described in this article is an improved technique compared to our previously described endoloop ligation method [12]. This device is commercially available for use in gastroenterology. Detachable loops have been used safely to ligate colonic polyps [22]. An advantage of using the PolyLoop over endoloop is the ability to adjust the loop size in the bladder. With endoloop, size of the loop can be decreased but cannot be increased if required, once the loop is inside the bladder. PolyLoop allows the flexibility of adjusting the loop size by moving the outer plastic sheath back and forth over the loop with the yellow cylinder. There is a possibility that the loop may not be detached after deployment, although it has not occurred in this short series. The loop can be cut with reusable loop cutter (Olympus: FS-5L/Q/U-1) (fig. 3) if it fails to detach. Additionally, PolyLoop is a pre-assembled device, whereas the endoloop technique requires passing an endoloop through a ureteric catheter prior to the procedure. Therefore, the PolyLoop is comparatively simpler and less time consuming in regards to preparation time.

The PolyLoop technique, like our previously described endoloop technique [12], ensures complete excision of distal ureter as the distal end is marked with the detachable loop. The distal ureteral stump is ligated prior to detaching the ureter or exposing the perivesical fat. This provides protection against urine spillage into perivesical space. There was no incidence of any perivesical recurrence in this short series. The results are similar to our earlier publication with endoloop technique [12].

This novel technique of PolyLoop ligation is a simple endoscopic approach for the management of the distal ureter during nephroureterectomy. However, this is a small series to draw any meaningful conclusions for the long-term oncological outcome. Further prospective research in this area is required to establish the most efficacious technique for the distal ureter management. 


\section{References}

-1 Munoz JJ, Ellison LM: Upper tract urothelial neoplasms: incidence and survival during the last 2 decades. J Urol 2000;164:1523-1525.

-2 Roupret M, Babjuk M, Comperat E, Zigeuner R, Sylvester R, Burger M, Cowan N, Böhle A, Van Rhijn BW, Kaasinen E, Palou J, Shariat SF: European guidelines on upper tract urothelial carcinomas: 2013 update. Eur Urol 2013;63:1059-1071

-3 Mullen E, Ahmed K, Challacombe B: Systematic review of open versus laparoscopic versus robot-assisted nephroureterectomy. Rev Urol 2017;19:32-43.

4 Aboumohamed AA, Krane LS, Hemal AK: Oncologic outcomes following robot-assisted laparoscopic nephroureterectomy with bladder cuff excision for upper tract urothelial carcinoma. J Urol 2015;194:1561-1566.

5 McDonald HP, Upchurch WE, Sturdevant CE: Nephro-ureterectomy: a new technique. J Urol 1952;67:804-809.

6 McDonald DF: Intussusception ureterectomy: a method of removal of the ureteral stump at time of nephroureterectomy without an additional incision. Surg Gynecol Obstet 1953;97:565-568.

7 McDougall EM, Clayman RV, Elashry O: Laparoscopic nephroureterectomy for upper tract transitional cell cancer: the Washington University experience. J Urol 1995; 154:975-980

$\checkmark 8$ Gill IS, Soble JJ, Miller SD, Sung GT: A novel technique for management of the en bloc bladder cuff and distal ureter during laparoscopic nephroureterectomy. J Urol 1999; 161:430-434
9 Wong C, Leveillee RJ: Hand-assisted laparoscopic nephroureterectomy with cystoscopic en bloc excision of the distal ureter and bladder cuff. J Endourol 2002;16:329-333.

10 Klingler HC, Lodde M, Pycha A, Remzi M, Janetschek G, Marberger M: Modified laparoscopic nephroureterectomy for treatment of upper urinary tract transitional cell cancer is not associated with an increased risk of tumour recurrence. Eur Urol 2003;44:442-447.

11 Vardi IY, Stern JA, Gonzalez CM, Kimm SY, Nadler RB: Novel technique for management of distal ureter and en block resection of bladder cuff during hand-assisted laparoscopic nephroureterectomy. Urology 2006;67:89-92.

12 Agarwal DK, Khaira HS, Clarke D, Tong R: Modified transurethral technique for the management of distal ureter during laparoscopic assisted nephroureterectomy. Urology 2008;71:740-743.

13 Hattori R, Yoshino Y, Komatsu T, Matsukawa Y, Ono Y, Gotoh M: Pure laparoscopic complete excision of distal ureter with a bladder cuff for upper tract urothelial carcinoma. World J Urol 2009;27:253-258.

-14 Mueller TJ, DaJusta DG, Cha DY, Kim IY, Ankem MK: Ureteral fibrin sealant injection of the distal ureter during laparoscopic nephroureterectomy - a novel and simple modification of the pluck technique. Urology 2010; 75:187-192.

15 Zou X, Zhang G, Wang X, Yuan Y, Xiao R,
Wu G, Long D, Xu H, Wu Y, Liu F: A oneport pneumovesicum method in en bloc laparoscopic nephroureterectomy with bladder cuff resection is feasible and safe for upper tract transitional cell carcinoma. BJU Int 2011;108:1497-1500.

16 Cormio L, Selvaggio O, Di Fino G, Massenio P, Annese P, de la Rosette J, Carrieri G: Transurethral distal ureter balloon occlusion and detachment: a simple means of managing the distal ureter during radical nephroureterectomy. J Endourol 2013;27:139-142.

17 Hetherington JW, Ewing R, Philp NH: Modified nephroureterectomy: a risk of tumour implantation. Br J Urol 1986;58:368-370.

18 Jones DR, Moisey CU: A cautionary tale of the modified "pluck" nephroureterectomy. $\mathrm{Br}$ J Urol 1993;71:486.

19 Arango O, Bielsa O, Carles J, GelabertMas A: Massive tumor implantation in the endoscopic resected area in modified nephroureterectomy. J Urol 1997;157:1839.

20 Ong AM, Bhayani SB, Pavlovich CP: Trocar site recurrence after laparoscopic nephroureterectomy. J Urol 2003;170:1301.

21 Ritch CR, Kearns JT, Mues AC, Hruby GW, Benson MC, McKiernan JM, Landman J: Comparison of distal ureteral management strategies during laparoscopic nephroureterectomy. J Endourol 2011;25:1149-1154.

22 Kaltenbach T, Milkes D, Friedland S, Soetikno R: Safe endoscopic treatment of large colonic lipomas using endoscopic looping technique. Dig Liver Dis 2008;40:958-961. 